Jurnal Abdidas Volume 2 Nomor 1 Tahun 2021 Halaman 34-40

JURNAL ABDIDAS

http://abdidas.org/index.php/abdidas

UNIVERSITAS

\title{
Pelatihan Kewirausahaan dan Manajemen Komunikasi Pemasaran bagi Pelaku UMKM pada Masyarakat di Kelurahan Ponggang, Kec. Serangpanjang, Kabupaten Subang
}

\author{
Ari Sulistyanto $^{1 凶}$, Dwinarko $^{2}$, Tabrani Syafrizal ${ }^{3}$, Saeful Mujab ${ }^{4}$ \\ Fakultas Ilmu Komunikasi, Universitas Bhayangkara Jakarta, Indonesia ${ }^{1,2,3,4}$ \\ E-mail: ari.sulstyanto@dsn.ubharajaya.ac.id ${ }^{1}$,dwinarko@dsn.ubharajaya.ac.id², \\ $\underline{\text { tabrani.syafriza@dsn.unharajaya.ac.id }}^{3}, \underline{\text { saeful.mujab@dsn.ubahrajaya.ac.id }}^{4}$
}

\begin{abstract}
Abstrak
Kewirausahaan yang dilakukan dalam bentuk UMKM (Usaha Mikro Kecil Menengah), apabila dikelola dengan baik dengan pengetahuan dan keterampilan manajemen yang modern dapat memberi nilai tambah ekonomi dan membuka lapangan kerja baru. Oleh karena itu, perlu pemberdayaan masyarakat untuk menumbuhkan dan meningkatkan kemampuan wirausaha masyarakat. Melalui metode pelatihan dalam bentuk ceramah, diskusi dan simulasi pada masyarakat dan unit UMKM Desa Ponggang, didapatkan hasil adanya peningkatan pemahaman dan kemampuan dalam kewirausahaan dan manajemen komunikasi pemasaran melalui platform digital e-commerce. Saran dalam kegiatan ini adalah perlunya pendampingan sebagai upaya monitoring terhadap keberhasilan program pengabdian masyarakat.
\end{abstract}

Kata kunci: pemberdayaan, komunikasi pemasaran, digital e-commerce

\section{Abstract}

Entrepreneurship that is carried out in the form of UMKM (Micro, Small and Medium Enterprises) if managed properly with modern management knowledge and skills can add economic value and open new jobs. Therefore it is necessary to empower the community to grow and improve the entrepreneurial skills of the community. Through training methods in the form of lectures, discussions and simulations to the community and the Ponggang Village UMKM unit, it was found that there was an increase in understanding and abilities in entrepreneurship and marketing communication management through the digital e-commerce platform. The suggestion in this activity is the need for assistance as an effort to monitor the success of community service programs.

Keywords: empowerment, marketing communications, digital e-commerce

Copyright (c) 2021 Ari Sulistyanto, Dwinarko, Tabrani Syafrizal, Saeful Mujab

$\triangle$ Corresponding author

Address : Kampus II Jl. Raya Perjuangan Bekasi Utara

Email : ari.sulistyanto@dsn.ubharajaya.ac.id

ISSN 2721- 9224 (Media Cetak)

DOI : https://doi.org/10.31004/abdidas.v2i1.199

ISSN 2721- 9216 (Media Online) 


\section{PENDAHULUAN}

Dalam peta jalan (road map) membangun pertumbuhan ekonomi Indonesia, dalam upaya meningkatkan kualitas kesejahteraan masyarakat adalah dengan pemberdayaan usaha terutama mikro, kecil, dan menengah (UMKM). Tetapi dilihat dari pertumbuhan UMKM, umumnya masih rendah dalam tingkat produktivitas, belum adanya kreativitas untuk meningkatkan nilai tambah, dan masihnya rendahnya kualitas produk yang dihasilkan. Akibatnya, pertumbuhan UMKM seperti jalan ditempat. Padahal, apabila dilakukan pemberdayaan maka tidak menutup kemungkinan menjadi pengerak utama ekonomi masyarakat (Andilala, 2020).

Situasi ini diperparah dengan adanya pandemik Covid-19. Oleh kerena itu, untuk menyiasati ledakan krisis ekonomi yang lebih besar di Indonesia, pemerintah telah menyoroti eksistensi dari Usaha Mikro Kecil dan Menengah (UMKM). Hal ini karena pemerintah untuk menjadikan UMKM sebagai penolong krisis ekonomi tidak lain karena adanya kontribusi UMKM di masa lampau.

Faktor penyebabnya dikarenakan, pertama, jiwa dan sikap sebagai seorang entrepreneurwirausaha belum dipandang sebagai pilihan utama dalam mata pencaharian. Mereka melakukan wirausaha sebagai kerja sampingan di tengahtengah perkerjaan tetap mereka sebagai karyawan paberik. Kedua, rendahnya pengetahuan pemasaran akan hasil produknya, yang sebatas untuk memenuhi kebutuhan di sekitar tempat tinggal. Padahal aspek penting dalam membangun usaha adalah membangun jaringan pasar, yaitu dengan membangun sistem promosi untuk penetrasi pasar dan mengelola jaringan pasar untuk mempertahankan pangsa pasar(Andilala, 2020).

Desa Ponggang adalah salah satu desa di Kecamatan Serangpanjang, Kabupaten Subang memiliki berbagai unit Usaha Mikro, Kecil, dan Menengah (UMKM), seperti pemotongan ayam, produksi keripik singkong maupun pisang, dan berbagai unit UMKM lain. Usaha yang dijalankan oleh UMKM sekarang ini masih terbatas dalam lingkup memenuhi kebutuhan masyarakat lokal. Lokasi Desa Ponggang, Kecamatan Serangpanjang, Kabupaten Subang. Desa Ponggang berada pada $+1 \mathrm{~km}$ dari Ibu kota Kecamatan Serang Panjang. Dari Kota Subang, menuju Desa Ponggang melalui transportasi darat dapat ditempuh kurang lebih antara 30 menit hingga 1 jam perjalanan. Dari data desa, ada sekitar 459.000 jiwa, dan tercatat ada sekitar 25 UMKM (Sunarya, 2020). Saat ini, baik dalam manajemen maupun pemasaran masih dilakukan secara manual. Oleh karena itu, untuk lebih meningkatkan produktivitas dan jangkauan pemasaran yang lebih luas, perlu adanya pelatihan manajemen komunikasi pemasaran sebagai bentuk upaya pemberdayaan.

Pemberdayaan merupakan upaya untuk meningkatkan taraf kehidupan masyarakat. Pada sisi tertentu, adanya kesulitan dalam meningkatkan kesejahteraan hidup, karena ketidaktahuan dan ketidakmampuan seseorang, sehingga kemiskinan dan keterbelakangan menjadi perangkap yang tidak bisa diselesaikan. Tujuan dari pemberdayaan 
adalah suatu kegiatan untuk memberi tahu dan berupaya membuat seseorang atau kelompok untuk mandiri. Menurut Shardlow, pemberdayaan merupakan upaya yang ditujukan pada individu, maupun kelompok, ataupun komunitas yang mempunyai komitmen dalam kehidupan dirinya untuk selalu mencapai taraf kehidupan dimasa depan yang sejahtera sesuai dengan kemampuan yang dimilikinya. Penjelasan ini, sebenarnya adalah adanya sumber daya untuk memberikan dorongan pada seseorang individu atau kelompok untuk bisa mengatasi hidup, agar lebih sejahtera dan bermartabat, agar bisa menyongsong kehidupan masa depan yang lebih baik(Adi, 2008).

Berkaitan dengan pemberdayaaan tersebut dalam memetakan permasalahan mitra mengenai pemberdayaan mengenai kewirausahaan dan manajemen komunikasi pemasaran UMKM Desa Ponggang, Kec. Serangpanjang, permasalahan yang dihadapi.

Pertama, jiwa, sikap dan pengetahuan mengenai kewirausahaan masih tradisional. UMKM yang tumbuh di Desa Ponggang, awalnya sebagai usaha sampingan ditengah pekerjaaan tetap mereka sebagai karyawan, buruh atau petani. Hal ini berakibat pada pertumbuhan UMKM yang lambat dan tidak terfokus. Penyebabnya karena ketidaktahuan dan ketidakmampuan dalam melihat, bahwa kewirausahaan yang dilakukan dalam bentuk UMKM, apabila dikelola dengan baik dengan pengetahuan dan keterampilan manajemen yang modern dapat memberi nilai tambah ekonomi dan membuka lapangan kerja baru.
Kedua, belum diterapkan manajemen komunikasi pemasaran secara terpadu. UMKM dalam memasarkan hasil produksi mereka masih terbatas pada pasaran lokal, karena keterbatasan pengetahuan akan manajemen komunikasi pemasaran. Pengenalan terhadap keberadaan teknologi komunikasi dengan mengenalkan $e$ commerce dengan berbagai aplikasi, setidaknya memberikan solusi terhadap keterbatasan pemasaran produk UMKM.

Pelaksanaan kegiatan PKM ini bertujuan untuk mendukung upaya meningkatkan kesejahteraan masyarakat, khususnya UMKM dan masyarakat Desa Ponggang agar termotivasi untuk bergerak dalam sektor kewirausahaan dalam bentuk UMKM.

Dengan demikian, melalui kegiatan pelatihan ini target yang hendak dicapai adalah: a) tumbuhnya jiwa kewirausahaan yang kreatif dan inovatif dalam menunjang pertumbuhan UMKM, b) kemampuan dalam pengelolaan UMKM dengan sistem manajemen modern yang mempermudah dalam pengembangan UMKM, baik dari sisi permodalan, produksi, dan pemasaran, c) kemampuan dalam penglolaan e-commerce dengan berbagai aplikasi platform e-commerce, d) kemampuan dalam pengelolaan melakukan promosi melalui platform media sosial.

\section{METODE}

Upaya untuk meningkatkan taraf kesejahteraan hidup masyarakat adalah dengan melakukan pemberdayaan agar terjadi perubahan pola pikir, sehingga berdaya dalam meningkatkan 
usaha taninya dan peningkatkan kemampuan dalam menjalankan usahanya.

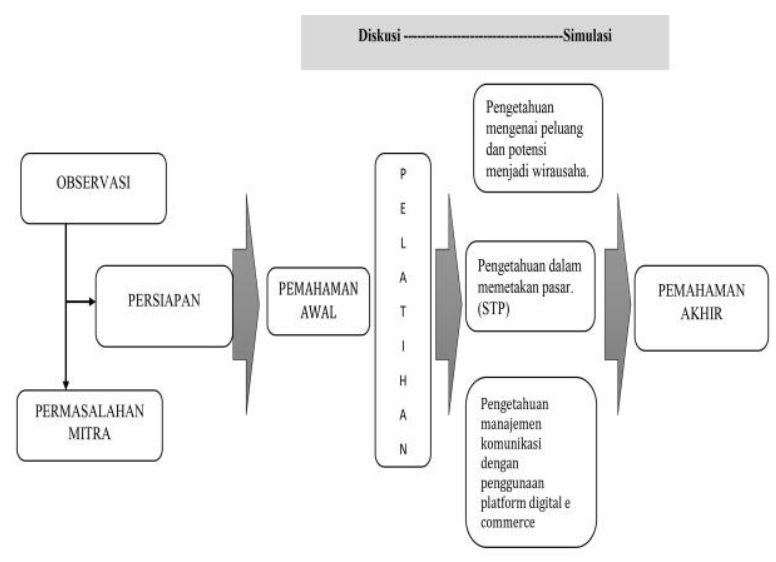

Gambar 1. Alur Metode Kegiatan

Kegiatan ini merupakan Program Kemitraan Masyarakat (PKM) Fakultas Ilmu Komunikasi, Universitas Bhayangkara Jakarta. Kegiatan diikuti 40 peserta, dengan rincian 25 barasal dari UMKM Desa Ponggang, 15 peserta dari masyarakat yang mempunyai kemauan untuk wirausaha. Kegiatan ini berlangsung ditengah masa pandemik covid 19 . Oleh karena itu, kegiatan dilakukan dengan protokol kesehatan yang ketat.

Dalam upaya peningkatan kesejahteran, dilakukan dengan pemberdayaan UMKM dan masyarakat. Kegiatan ini dilakukan dengan metode pelatihan. Dalam pelatihan, dilakukan dengan 4 sesi. Pertama, adalah menggali pemahaman mengenai kemauan dan minat kewirausahaan, dan kemampuan dalam manajemen komunikasi pemasaran. Kedua, dilakukan dengan sesi ceramah dan diskusi. Ketiga, sesi simulasi. Keempat, melakukan pengukuran pemahaman terhadap materi yang sudah disajikan.
Tabel 1. Materi Pelatihan

\begin{tabular}{|c|c|}
\hline Materi & Indikator \\
\hline $\begin{array}{l}\text { Pengetahuan } \\
\text { mengenai peluang } \\
\text { usaha dan potensi } \\
\text { menjadi wirausaha }\end{array}$ & $\begin{array}{l}\text { 1. Adanya motivasi untuk } \\
\text { mengembangkan diri } \\
\text { 2. Adanya kemauan untuk } \\
\text { melakukan wirausaha }\end{array}$ \\
\hline $\begin{array}{l}\text { Pengetahuan dalam } \\
\text { menentukan pasar } \\
(\mathrm{STP})\end{array}$ & $\begin{array}{l}\text { 1. } \text { Mampu melakukan } \\
\text { segmentasi pasar sesuai } \\
\text { dengan produk yang } \\
\text { dihasilkan } \\
\text { 2. Mampu melakukan } \\
\text { menentukan target } \\
\text { konsumen sesuai dengan } \\
\text { produk yang dihasilkan }\end{array}$ \\
\hline $\begin{array}{l}\text { Pengetahuan } \\
\text { manajemen } \\
\text { komunikasi dengan } \\
\text { penggunaan } \\
\text { platform digital e- } \\
\text { commerce }\end{array}$ & $\begin{array}{l}\text { 1. Pengenalan terhadap } \\
\text { platform e-commerce dan } \\
\text { media sosial untuk } \\
\text { pemasaran produk } \\
\text { 2. Mampu menggunakan } \\
\text { atau mengoperasikan } \\
\text { berbagai platform e- } \\
\text { commerce }\end{array}$ \\
\hline
\end{tabular}

\section{HASIL DAN PEMBAHASAN}

Dalam kegiatan pelatihan ini, untuk mengetahui kemampuan anggota UMKM mengenai kewirausahaan dan manajemen komunikasi pemasaran. Sebelum diadakan pelatihan, dilakukan pengukuran terhadap pemahaman dan kemampuan peserta. Hasil dari pengukuran dari pemahaman awal sebesar $53.8 \%$. Setelah pelatihan dilakukan, pemahaman meningkat menjadi $79.6 \%$. Detail mengenai pemahaman peserta pelatihan kewirausahaan dan manajemen komunikasi pada UMKM dapat dilihat pada gambar 2.

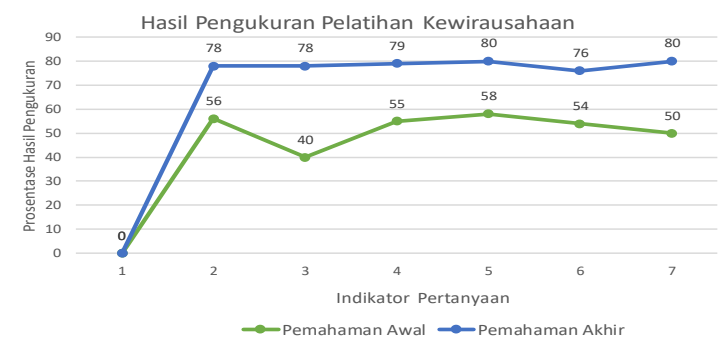

Gambar 2. Tingkat Pemahaman 
Materi mengenai menumbuhkan minat wirausaha, dilakukan dengan memberi contoh keberhasilan dari para pelaku usaha yang sudah sukses. Tujuan dari materi ini adalah untuk memberikan motivasi, agar ada kemauan untuk terjun dalam wirausaha, untuk meningkatkan kesejahteraan ekonomi.

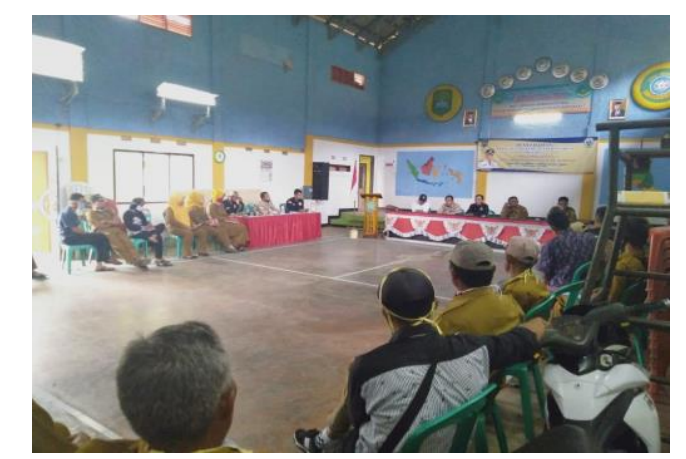

Gambar 3. Suasana Pelatihan di Aula Desa Ponggang

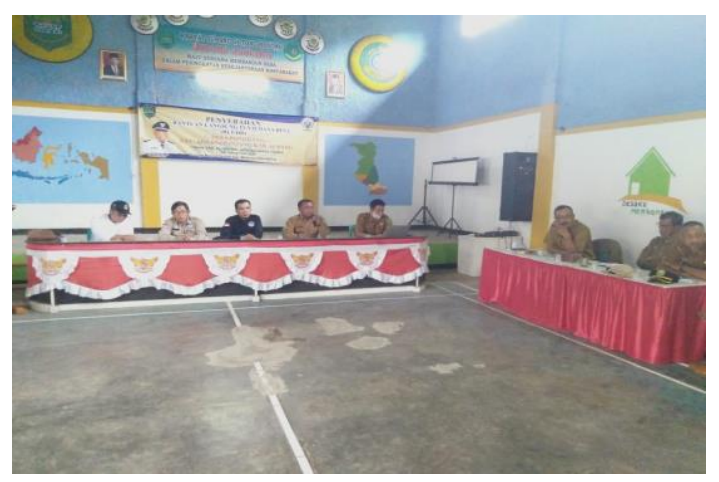

Gambar 4. Suasana Pelatihan di Aula Desa Ponggang

Dalam materi mengenai potensi pasar dalam digital e-commerce, materi berdasarkan pada konsep STP, yaitu Segmentasi, Targeting, Dan Posisioning (Kotler, 2009). Tujuan dari materi ini adalah agar peserta pelatihan UMKM dapat membedakan dan menentukan target pasar potensial, sehingga dapat memperoleh hasil penjualan yang maksimal. Dalam materi ini juga memberi pengetahuan bahwa dalam pasar digital, konsumen sangat besar, dan luas tanpa dibatasi oleh jarak. Oleh karena itu, penentuan target pasar yang jelas akan memudahkan dalam pemasaran produk.

Dalam materi ini, diperkenalkan dengan berbagai platform digital e-commerce, seperti GoFood untuk UMKM yang bergerak dibidang makanan, Bukalapak yang bisa untuk memasarkan hasil kerajinan. Dalam sesi pelatihan, dilakukan simulasi dengan melakukan pendaftaran, dan kemudian bisa melakukan akses, mengoperasikan serta menampilkan produk digital e-commerce.

Pelatihan ini penting diperkenalkan pada anggota UMKM. Hal ini dilatarbelakangi dengan alasan bahwa saat ini merupakan era revolusi 4.0. Dalam era ini, transaksi bisa dilakukan di ruang virtual (J. Allen, 2018). Keadaan ini mengharuskan para pelaku usaha untuk menyesuaikan. Ada beberapa hal yang menguntungkan dengan perdagangan dengan sarana teknologi komunikasi atau dikenal dengan e-commerce. Ada beberapa keuntungan yang didapatkan dari e-commerce (William H. DeLone \& Ephraim R. McLean, 2014). Pertama, menjual produk atau jasa secara online tanpa harus mendirikan toko atau kantor besar seperti yang dilakukan oleh para pelaku bisnis offline sebagai tempat usaha sehingga bisa menekan modal yang dikeluarkan dan dengan memanfaatkan jaringan internet, bisa memasarkan produk atau jasa kepada konsumen tanpa dibatasi ruang dan waktu. Kedua, kemudahan berkomunikasi antara penjual dan pembeli, dan dalam pemasaran barang juga jauh lebih 
menguntungan karena tidak perlu mengeluarkan biaya tinggi untuk melakukan promosi, dengan platform media berbasis teknologi komunikasi bisa memasarkan produk atau jasa secara meluas ke masyarakat.

Alasan yang lain, yaitu menyesuaikan dengan target pemerintah untuk membuat pelaku UMKM bisa memanfaatkan dunia digital, seperti e-commerce dalam mengembangkan usahanya. Data dari, Kementerian Koperasi RI melaporkan sebanyak 3,79 juta Usaha Mikro, Kecil, dan Menengah (UMKM) sudah memanfaatkan platform online dalam memasarkan produknya. Jumlah ini berkisar 8 persen dari total pelaku UMKM yang ada di Indonesia, yakni 59,2 juta. Angka ini diharapkan untuk terus bertambah karena tingginya jumlah UMKM yang Go-Digital, sejalan dengan tujuan pemerintah yang ingin menjadikan Indonesia sebagai Digital Energy of Asia tahun 2020 mendatang(Yuliani, 2020).

Usaha Mikro, Kecil, dan Menengah (UMKM) Indonesia memberikan kontribusi besar terhadap Produk Domestik Bruto (PDB). Saat ini, UMKM Indonesia menyumbangkan hingga Rp 8.573,9 triliun ke PDB Indonesia (atas dasar harga berlaku) pada 2018. PDB Indonesia pada 2018 sebesar Rp 14.838,3 triliun, maka kontribusi UMKM mencapai 57,8\% terhadap PDB (Jayani, 2020). Di samping itu, dari sisi lapangan kerja, UMKM mampu membuka lapangaan pekerjaan sebanyak 116.978.631 orang atau mencapai 97\% dari total tenaga kerja Indonesia (UMKM dan Unit Besar). Sampai saat ini, UMKM Indonesia sebanyak 64.194.057 unit atau $99,99 \%$ dari total unit usaha di Indonesia (Jayani, 2020).

Metode pemberdayaaan masyarakat dengan strategi pelatihan dalam berbagai kegiatan pengabdian mempunyai dampak yang positif. Hal ini diperlihatkan pada tahap pemahaman awal hanya $53.8 \%$. Setelah diadakan pelatihan dengan model ceramah, diskusi dan simulasi, pemahaman meningkat sebesar $79.6 \%$. Metode ini juga mempunyai hasil yang signifikan pada kegiatan yang lain. Seperti dilakukan dalam strategi peningkatan pemberdayaan ekonomi masyarakat melalui zakat di Desa Taluduyunu (Simanjuntak et al., 2020). Begitu juga dengan kegiatan pelatihan pembuatan media pembelajaran matematika pada materi penjumlahan dan perkalian di SD AzZahrab. Berbagai kegiatan masyarakat, hasil memperlihatkan media pembelajaran sangat berguna untuk membantu proses pembelajaran agar proses pembelajaran menjadi menarik, merubah materi matematika yang sulit menjadi lebih mudah, dan pada akhirnya nilai matematika siswa meningkat (Harahap, 2020).

Dalam kegiatan ini, memang tidak cukup dengan pelatihan. Kendati dari hasil pemahaman akhir menunjukan hasil yang positif atau masih menunjukkan hasil dalam taraf kognitif. Untuk keberlanjutan program, perlu ada dampak yang mengarah pada suatu tindakan nyata dari peserta pelatihan. Oleh karena itu, dalam program kegiatan selanjutnya diadakan monitoring dengan metode pendampingan. 
Masyarakat di Kelurahan Ponggang, Kec. Serangpanjang, Kabupaten Subang- Ari Sulistyanto,

Dwinarko, Tabrani Syafrizal, Saeful Mujab

DOI: https://doi.org/10.31004/abdidas.v2i1.199

\section{SIMPULAN}

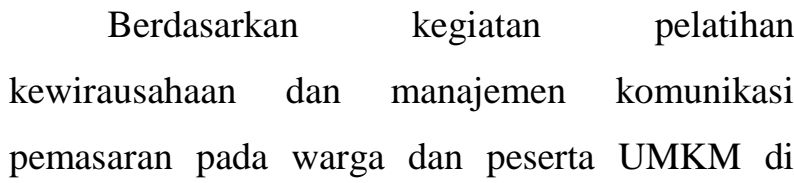

Desa Ponggang, Kecamatan Serangpanjang,

Kabupaten Subang, dapat disimpulkan sebagai berikut:

1. Dalam kegiatan pelatihan, adanya peningkatan pemahaman dan kesadaran dalam kewirausahaan untuk meningkatkan kesejahteraan ekonomi keluarga. Bagi peserta yang sudah terjun dalam UMKM mempunyai kemauan untuk memperbesar usaha.

2. Adanya kemampuan dalam melakukan pemetaan pasar bagi usahanya. Yakni dalam menentukan target dan memperbesar konsumen.

3. Para peserta sudah mengenal dan mampu melakukan transaksi dengan platform digital e-commerce.

\section{DAFTAR PUSTAKA}

Adi, I. R. (2008). Intervensi Komunitas Pengembangan Masyarakat. PT Raja Grafindo Persada.

Andilala. (2020). Upaya pemerintah memaksimalkan peran UMKM di masa pandemi COVID-19. Antara.Com.

Harahap, R. (2020). Pelatihan Pembuatan Media Pembelajaran Matematika pada Materi Penjumlahan dan Perkalian di SD Az-Zahra. Jurnal Abdidas, 1(6), 498-503.

J. Allen, et. a. (2018). Understanding the impact of e-commerce on last-mile light goods vehicle activity in urban areas: The case of London. Transportation Research Part D: Transport and Environment, 61(June), 325-
338. https://doi.org/10.1016/j.trd.2017.07.020

Jayani, D. H. (2020). Berapa Sumbangan UMKM Terhadap Perekonomian Indonesia? Databoks. https://databoks.katadata.co.id/datapublish/20 20/05/20/berapa-sumbangan-umkmterhadap-perekonomian-indonesia\#

Kotler, P. \& K. L. K. (2009). Marketing Management (Twelfth Ed). New Jersey: Pearson.

Simanjuntak, E. Y. B., Silitonga, E., \& Aryani, N. (2020). Jurnal abdidas. Jurnal Abdidas, 1(3), 119-124.

Sunarya, A. (2020). Laporan Kerja Badan Usaha Milik Desa (BUMDES) Tahun2019-2020 (28/LK_Bumdes/8/2020).

William H. DeLone \& Ephraim R. McLean. (2014). Measuring e-Commerce Success: Applying the DeLone \& McLean Information Systems Success Model. International Journal of Electronic Commerce, 9(1), 3147.

https://doi.org/10.1080/10864415.2004.1104 4317

Yuliani, A. (2020). Kemenkop UKM: 3,79 Juta UMKM Sudah Go Online. Kementerian Komunikasi Dan Informatika. https://www.kominfo.go.id/content/detail/115 26/kemenkop-ukm-379-juta-umkm-sudahgo-online/0/sorotan_media 